\title{
Should Early Prone Positioning Be a Standard of Care in ARDS With Refractory Hypoxemia?
}

\author{
John J Marini MD, Sean A Josephs MD, Maggie Mechlin MD, and William E Hurford MD
}

\author{
Introduction \\ Prone Positioning as a Standard for ARDS-Pro \\ Prone Positioning as a Standard for ARDS-Con
}

\begin{abstract}
For the past 4 decades, the prone position has been employed as an occasional rescue option for patients with severe hypoxemia unresponsive to conventional measures applied in the supine orientation. Proning offers a high likelihood of significantly improved arterial oxygenation to well selected patients, but until the results of a convincing randomized trial were published, its potential to reduce mortality risk remained in serious doubt. Proning does not benefit patients of all disease severities and stages but may be life-saving for others. Because it requires advanced nursing skills and escalation of monitoring surveillance to deploy safely, its place as an early stage standard of care depends on the definition of that label. Key words: prone position; refractory hypoxemia; ARDS; mechanical ventilation; respiratory failure; secretion clearance. [Respir Care 2016;61(6):818-829. (C) 2016 Daedalus Enterprises]
\end{abstract}

\section{Introduction}

ARDS was initially reported with mortality as high as 90\%. ${ }^{1}$ Although outcome has improved in recent decades, ARDS mortality currently approximates 27,32 , and $45 \%$ for patients with $\mathrm{P}_{\mathrm{aO}_{2}} / \mathrm{F}_{\mathrm{IO}_{2}}$ of 200-300, 100-200, and $<100 \mathrm{~mm} \mathrm{Hg}$, respectively. ${ }^{2}$ Continued high mortality warrants ongoing research efforts for alternative therapeutic

Dr Marini is affiliated with the University of Minnesota, Minneapolis, Minnesota and with the Pulmonary and Critical Care Department of Regions Hospital, St. Paul, Minnesota. Drs Josephs, Mechlin, and Hurford are affiliated with the Department of Anesthesiology, University of Cincinnati, Cincinnati, Ohio.

Drs Marini and Hurford presented a version of this paper at the 54th ResPiRATORY CARE Journal Conference, "Respiratory Care Controversies III," held June 5-6, 2015, in St Petersburg, Florida.

Correspondence: John J Marini MD, Regions Hospital MS11203B, 640 Jackson Street, Street Paul, MN 55101. E-mail: marin002@umn.edu.

The authors have no conflicts to disclose.

DOI: $10.4187 /$ respcare. 04562 strategies and modalities. Relatively consistent improvement in mortality has been demonstrated through randomized controlled trials and meta-analyses with low tidal volume mechanical ventilation ${ }^{3-6}$ Other interventions, such as the targeting of an "open lung" with higher than traditional PEEP and the use of neuromuscular blockade, have somewhat less convincing evidence for therapeutic effect. ${ }^{7-9}$

Prone positioning for ARDS has been extensively studied in the laboratory and at bedside, and in both settings, it improves oxygenation and lung recruitment during acute lung injury. ${ }^{10-13}$ Although multiple large randomized controlled trials conducted in diverse populations failed to demonstrate a consistent mortality benefit to prone positioning in ARDS, ${ }^{14-18}$ one published trial reported a very substantial improvement in mortality (Fig. 1). ${ }^{20}$ Based on these results, many would recommend widespread adoption of prone positioning as a standard for patients with ARDS who fail to respond to usual therapy. Indeed, proning, an intervention that imposes some risk for adverse events, has been adopted by some hospitals for all of those patients categorized as refractory to conventional measures. The mortality outcome benefit of prone positioning, however, has been most evident in selected patient popu- 


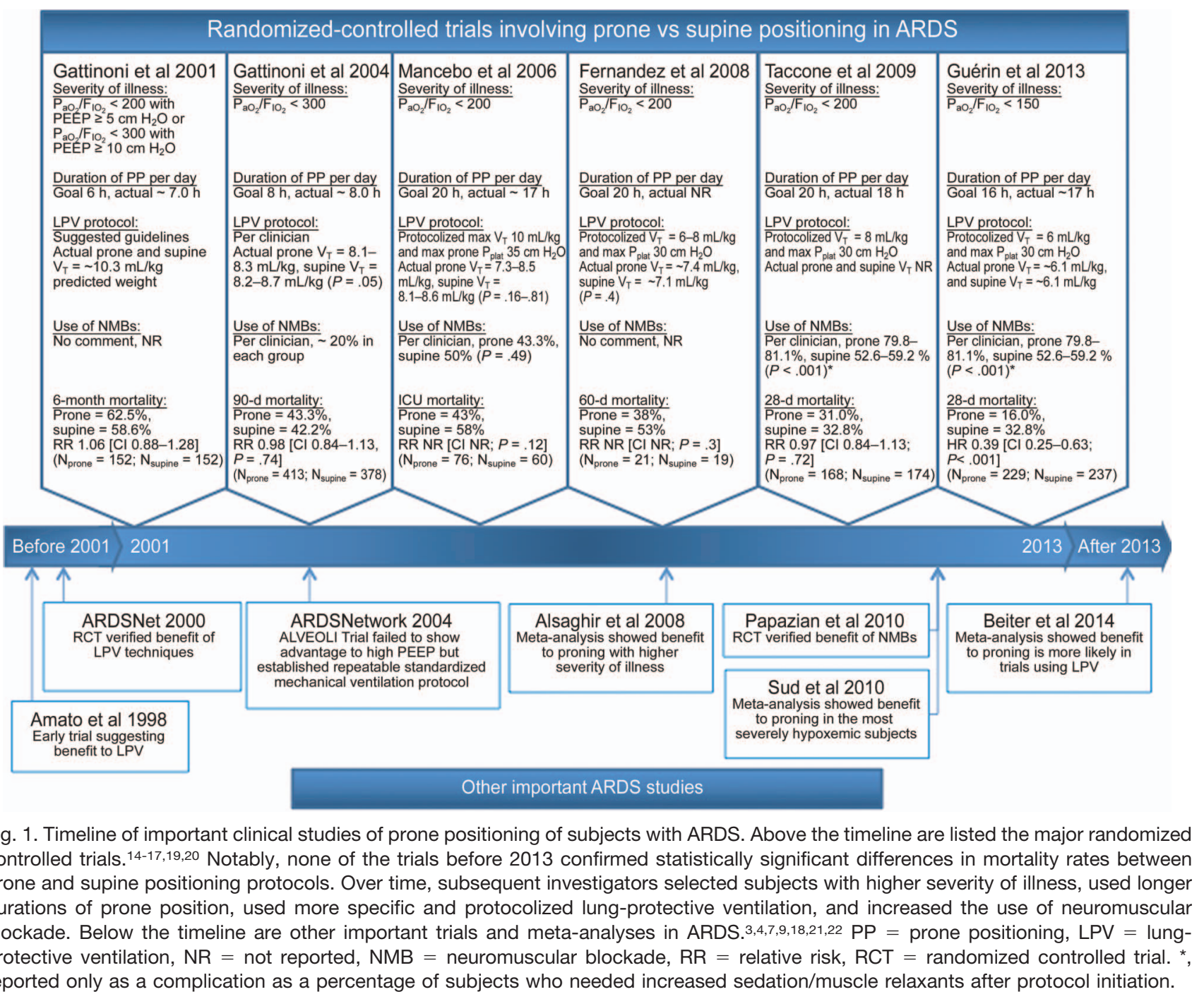

lations, and alternatives to proning exist with a demonstrated potential to improve refractory hypoxemia. It is therefore reasonable to argue that prone positioning should not be considered as a care standard but rather should be restricted to very specific care settings and phases of illness. What follows is a description of the rationale and evidence on both sides of the argument.

\section{Prone Positioning as a Standard for ARDS-Pro}

Variation of body position is innate to healthy patients, but caregivers typically orient critically ill patients in the face-forward, semi-recumbent posture for days to weeks on end, with only periodic repositioning side-to-side through a relatively shallow arc during the first phase of illness. Doing so allows access to vital structures (airway, oropharynx, and vasculature) and allows the caregiver to face the patient as we are accustomed to do in everyday life. However, from the standpoints of comparative anatomy and animal behavior, this practice of enforcing prolonged bed rest in the supine position has no parallel, since virtually all mammals adopt a prone position when awake to protect vulnerable and vital ventral structures. Our evolutionarily close primate cousins do the same and ambulate prone.

The apparent exceptions to this rule are bats and some arboreal animals (eg, sloth and opossum) who hang during rest at an inaccessible height for protection. It is notable that humans, when recumbent, most frequently assume a lateral position to initiate sleep and orient themselves prone almost as often as supine. ${ }^{23}$

Experimental data ${ }^{24,25}$ and clinical observations ${ }^{26-28}$ demonstrate uncontestable physiologic benefit from prone positioning during acute lung injury. It is clear that prone positioning redistributes stretching (transpulmonary) forces within the thoracic cavity, helping to recruit lung tissue, 


\section{EARly Prone Positioning IN ARDS}

gravitationally drain the airways, and improve match-up of ventilation to perfusion. ${ }^{12,29}$ For the same tidal volume and PEEP combination, ventilating large animals in the prone position reduces the severity of ventilator-inflicted lung damage. ${ }^{24,30,31}$

Using the very high but irrefutable outcome threshold of improved overall mortality, most large clinical trials conducted over the last $20 \mathrm{y}$ were unable to confirm a survival benefit in diverse populations of subjects labeled as having acute lung injury/ARDS. ${ }^{14-17}$ Clearly, not everyone benefits from face-down positioning, yet post-trial subgroup analyses have hinted that certain patient subgroups might indeed benefit from the prone orientation. ${ }^{14}$ Severely ill patients, those experiencing improved $\mathrm{CO}_{2}$ exchange after proning, and those ventilated with large and presumably more hazardous tidal volumes appeared more likely to benefit than other members of the general cohort. ${ }^{32}$ Metaanalyses of pooled data from prone positioning trials have appeared over the past several years that focus attention on those relative few with the worst oxygen exchange. ${ }^{18,33}$ These analyses argue convincingly that although proning cannot be recommended for all patients with acute lung injury, it does hold therapeutic value for some.

With the ascendance of evidence-based approaches to medical practice, clinicians have come to depend on randomized clinical trials (RCTs) to confirm or refute the value of therapeutic options used in medical practice. ${ }^{34}$ Although RCTs are of unquestioned benefit when realistic outcome variables and mechanistically sound trial design are applied to an appropriate population, numerous failed trials conducted in critical care settings demonstrate how vulnerable RCTs are to imprecise definitions, loose selection criteria, incomplete physiological understanding, and restricted availability of suitable subjects. In the wake of an RCT that fails to demonstrate outcome benefit, an intervention of lifesaving value for a well selected few may be shelved for lack of definitional precision and sufficient numbers.

Prone positioning provides an illuminating example. The truncated cone-shaped lung must fit into the more cylindrically contoured chest cavity, and this shaping mismatch is partially offset by the reconfiguration of the latter when prone. ${ }^{12,35}$ Physiologic benefit follows as a direct consequence of assuming what for all other mammals is the preferred orientation (Table 1). There is little question that prone positioning can be expected to redistribute translung forces, reduce the supine gradient of trans-lung pressure, ${ }^{11,36}$ recruit and stabilize dorsal lung units, relieve cardiac compression of lung tissue, ${ }^{28}$ and favor mouthward migration of retained airway secretions. ${ }^{37}$ Such actions, on average, reliably improve oxygenation and airway drainage, particularly in the earlier stages of the injury process. The consistently quoted response rate is approximately $70 \% .^{38}$ The more even distribution of trans-alve-
Table 1. Physiologic Sequelae of Assuming the Prone Position

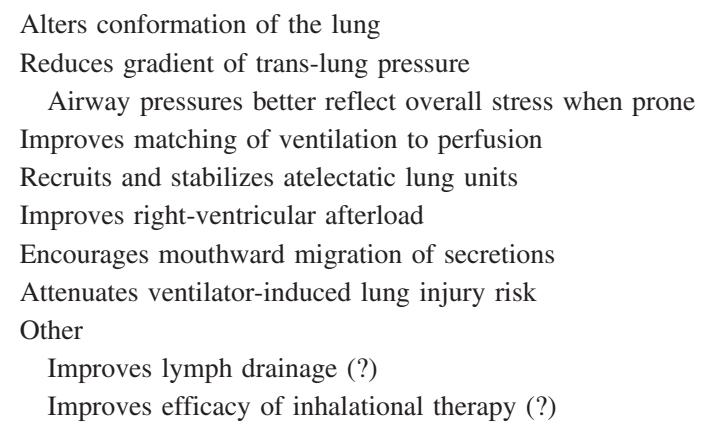

olar pressure accomplished by the prone-modified chest wall may reduce the impact of stress focusing at the junctions of closed and open alveoli, ${ }^{39}$ reduce the tendency for airway opening and closure, allow the use of less PEEP, improve afterload to the right ventricle, ${ }^{40,41}$ and permit reduction of potentially toxic concentrations of inspired oxygen. To achieve a survival benefit, it would appear from published data that the patient should be positioned prone for the majority of the day for at least several days. However, although investigators of proning mechanisms agree in their observations and principles of application and management, more precision is needed to guide care. Currently, we know neither the optimal daily duration of prone positioning nor when to initiate prone positioning nor, once applied, how many days to persist with it. It is quite possible that reversion to the supine position for a few hours once daily is beneficial. Finally, the interactions of prone positioning with varied co-interventions, such as recruiting maneuvers, $\mathrm{F}_{\mathrm{IO}_{2}}$, and driving pressure, ${ }^{42}$ are little studied.

Although many nursing units are now proficient in accomplishing and managing the prone position when indicated, ${ }^{43}$ experience has shown that proning holds the potential for harm as well as good. Stringent precautions must be observed to prevent pressure ulcers, especially over the face and eyes, with care taken to avoid inadvertent misadventures with displaced or kinked tubes and catheters. Such problems often occur during the initial transition to the prone position and often relate to patient discomfort as well as the duration of prone positioning. Well maintained sedation helps in avoiding the high transpulmonary forces encountered during forceful breathing. In theory, mobile and gravity-driven biofluids (infected secretions and mediator-rich, surfactant-inhibiting edema of first-phase inflammation) migrating along the airway have the potential to propagate initially focal injury or infection from dorsal to more ventral zones. ${ }^{37,44}$

Clues from the first large Italian trial ${ }^{14}$ of prone positioning suggested that with mortality reduction as the ob- 


\section{Early Prone Positioning IN ARDS}

jective, only restricted subsets of patients-those with the most severe disease and those who are recruitable-are good candidates. The prospective follow-up RCT of prone positioning conducted in subjects with ARDS with moderate to severe hypoxemia affirmed that potential benefits are most likely to accrue to those most severely affected. ${ }^{17}$ The signal indicating mortality benefit, although clearly present, was not overwhelmingly strong and would have required the enrollment of many more subjects for the trend to reach statistical significance. Lung-protective measures, implemented before study initiation, might have damped the risk for ventilator-induced lung injury and masked any benefit from proning maneuvers. Indeed, the overall mortality of ARDS in the age of lung-protective strategies has progressively declined. ${ }^{45}$

Recruitment potential tends to parallel severity of disease, defined and categorized by impaired oxygenation as defined according to the Berlin Consensus. ${ }^{46}$ Even severe hypoxemia, however, may itself be too inclusive a category to identify those most amenable to prone positioning. The key to survival benefit is unlikely to be improved oxygen exchange, which occurs in most proned patients and can be achieved without altering lung stress, strain, or driving pressure simply by better mixed venous saturation and redistributing perfusion without increasing the number of functional lung units. As suggested by the earlier analysis by Gattinoni et al, ${ }^{32}$ recruitment may be the characteristic that determines prone positioning's value, and "recruitable" patients are only a subset of those with severe hypoxemia. Interestingly, the percentage of consolidated tissue that is recruitable is higher in the most severely affected patients. Recruitability is also a closer correlate of mortality than is calculated tissue strain. ${ }^{47}$ Achieving recruitment tends to improve pulmonary vascular resistance and thereby aid right ventricular performance. As argued forcefully by Vieillard-Baron et al, ${ }^{41}$ such improvement tends to occur when the central circulation is not already full in the supine orientation (ie, there is some preload reserve). Quantitating tissue recruitment at the bedside remains elusive in today's medical practice, but techniques that are just now coming online for tracking regional events within the injured lung, such as electrical impedance tomography and lung ultrasonography, raise hopes for better precision and logistical feasibility.

The remarkably positive results of the PROSEVA trial ${ }^{20}$ demonstrate that failed RCTs do not invalidate prone positioning as a tool for ARDS management. Careful metaanalyse ${ }^{18}$ clearly demonstrate that prone positioning can be life-saving if the patients are well selected and the timing of the intervention is appropriate. Guérin and colleague ${ }^{20}$ followed the clues provided by prior trial results, selected a severely affected population, treated them at an early time, silenced neuromuscular efforts, and maintained the prone positioning for the great majority of care hours during the crucial period. Such results suggest but do not establish rigid rules by which to guide practice. In the absence of unassailable RCT guidance, there are few absolute mandates or prohibitions; the decision to implement prone positioning remains a matter of individual judgment, tempered by empiricism. Unless otherwise contraindicated, prudent lessons from available data point toward undertaking an empirical trial of prone positioning in those receiving ventilatory support whose severely impaired oxygenation fails to respond to usual measures, including sedation, recruiting maneuvers, and high PEEP. Because misadventures may arise during prone positioning, proning should be limited to those with severe ARDS (as indicated by $\mathrm{P}_{\mathrm{aO}} / \mathrm{F}_{\mathrm{IO}_{2}}<100 \mathrm{~mm} \mathrm{Hg}$ ) who show convincingly positive recruiting responses within a few hours of being turned. Even when successful, prone positioning seldom maintains its strong advantage over supine positioning longer than 3-4 d, a period over which patients who benefit from prone positioning usually undergo improvement in the underlying process of lung injury. ${ }^{14}$ Although $\mathrm{P}_{\mathrm{aO}_{2}}$ may adequately classify disease severity, $\dot{\mathrm{V}}_{\mathrm{E}} / \mathrm{P}_{\mathrm{aCO}_{2}}$ better tracks gas exchanging efficiency and perhaps better reflects the recruitment that appears to be central to prone positioning benefit. ${ }^{48}$ Recruiting maneuvers are employed after prone positioning, both for their potential to reopen refractory units and for setting the appropriate level of PEEP. ${ }^{49,50}$

Recent years have seen important advances in deploying a safe and effective extrapulmonary gasexchanging methodology. ${ }^{51}$ This availability provides a potent and valued alternative option to achieve acceptable oxygenation for the rescue phase of ARDS. The extrapulmonary gas-exchanging methodology also may reduce minute ventilation requirements and therefore help to limit patient exposure to damaging airway pressures. However, an extrapulmonary gas-exchanging methodology is relatively expensive to implement, requires specialized expertise to conduct safely, and does expose the patient to systemic risks, such as bleeding, infection, and mediator release and activation within the bloodstream. By comparison, prone positioning is inexpensive, relatively safe, and requires only standard nursing skills once prone positioning has been accomplished. It should be noted that an extrapulmonary gas-exchanging methodology can be used in the prone as well as supine position, once the catheter has been inserted. Proning clearly is not to be used in every patient with acute lung injury, but it should be promoted as a helpful, even life-saving, and routinely considered option for those most likely to succumb to this devastating problem. In a strong sense, early prone position should be a standard of care in ARDS with refractory hypoxemia. 


\section{Prone Positioning as a Standard for ARDS-Con}

The influential prospective PROSEVA trial by Guérin et $\mathrm{a}^{20}$ reported major risk reductions for 28 - and $90-\mathrm{d}$ mortality in subjects with severe ARDS who had been proned for extended diurnal periods during the first phase of their illness. It is primarily this report that has returned the practice of proning patients with ARDS to the forefront of discussions of critical care therapeutics. These French investigators randomized 466 subjects into an intervention group $(n=237)$ that received $4 \pm 4$ sessions of $17 \pm 3 \mathrm{~h}$ in the prone position. Both the control supine group $(n=229)$ and the prone group were ventilated with a lung-protective ventilation protocol that included targeting initial tidal volumes $\left(\mathrm{V}_{\mathrm{T}}\right)$ of $6 \mathrm{~mL} / \mathrm{kg}$ of ideal body weight in most subjects as well as observing paired $\mathrm{PEEP} / \mathrm{F}_{\mathrm{IO}_{2}}$ settings and absolute limits of plateau pressures of $30 \mathrm{~cm} \mathrm{H}_{2} \mathrm{O}$. Both groups were similar, except that the supine group had higher mean Sequential Organ Failure Assessment scores, greater use of vasopressors, and less use of neuromuscular blocking agents (NMBAs) before inclusion. Once subjects were entered into the protocol, however, NMBAs were used for significant and similar durations in both groups $(5.7 \pm 4.7$ and $5.6 \pm 5.0 \mathrm{~d})$. There were no differences in complications between groups, save for more cardiac arrests in the supine cohort.

Several randomized controlled trials of prone positioning in ARDS before that of Guérin et $\mathrm{al}^{20}$ failed to show a statistically significant effect on survival in other populations managed differently. In 2001, Gattinoni et al ${ }^{14}$ published the first major randomized controlled trial to report on the effect of prone positioning in ARDS. In this study, subjects with $\mathrm{P}_{\mathrm{aO}} / \mathrm{F}_{\mathrm{IO}_{2}}<200$ with PEEP $\geq 5 \mathrm{~cm} \mathrm{H}_{2} \mathrm{O}$ or $\mathrm{P}_{\mathrm{aO}_{2}} / \mathrm{F}_{\mathrm{IO}_{2}}<300$ with PEEP $\geq 10$ were randomized to supine $(n=152)$ or prone $(n=152)$ groups. ${ }^{14}$ Although these inclusion criteria did not comply with the diagnostic definition of ARDS, only 5.3 and $6.6 \%$ in the prone and supine groups would have failed to meet the current official definition of ARDS. ${ }^{2}$ In the intervention group, subjects were placed in the prone position for $6 \mathrm{~h} / \mathrm{d}$ for up to $10 \mathrm{~d}$. The 10-d mortality rate, which was the primary end point in this study, was not statistically different between the 2 groups. ${ }^{14}$ It should be noted that this trial was completed before the ARDSNet low tidal volume trial was reported. ${ }^{3}$ As such, clinicians were asked to use the American-European Consensus Conference guidelines on mechanical ventilation. ${ }^{1}$ These guidelines allowed for plateau pressures of $>35 \mathrm{~cm} \mathrm{H}_{2} \mathrm{O}$ but encouraged smaller $\mathrm{V}_{\mathrm{T}}$ to prevent severely high pressures. Unfortunately, details of the mechanical ventilation that subjects actually received were not reported. There was a significant increase in prone-related pressure ulcers, but inadvertent airway events (such as unplanned extubations) were the same in both groups.
In a study that preceded their landmark paper, Guérin et $\mathrm{al}^{15}$ performed a second trial that failed to show a mortality benefit for prone positioning in ARDS. This large trial randomized a total of 791 subjects with ARDS (as defined by $\left.\mathrm{P}_{\mathrm{aO}_{2}} / \mathrm{F}_{\mathrm{IO}_{2}}<300\right)$ to prone $(n=413)$ and supine $(n=378)$ positioning. Subjects in the prone group were placed in the prone position for a median of $8 \mathrm{~h} / \mathrm{d}$ for a median of 4 d. ${ }^{15}$ Mortality rates at $28 \mathrm{~d}$ were 31.5 and $32.4 \%$ in the supine and prone groups, respectively. This trial encountered substantially higher rates of selective (mainstem) intubation, endotracheal tube obstruction, and pressure ulcers among the group that were proned. ${ }^{15}$

After these 2 trials failed to show a mortality benefit for prone positioning in ARDS, Mancebo et al ${ }^{16}$ designed a trial, theorizing that previous investigators had not implemented prone therapy early enough or long enough to show an effect. Mancebo et al ${ }^{16}$ compared the ICU mortality of subjects with ARDS placed in the supine $(n=60)$ and prone $(n=76)$ position for a targeted $20 \mathrm{~h} / \mathrm{d}$ for up to $10 \mathrm{~d}$. Subjects were actually proned for a mean of $17 \mathrm{~h} / \mathrm{d}$ for a mean of $10 \mathrm{~d}$. ICU mortality was 58 and $43 \%$ in the supine and prone groups, respectively $(P=.12) .{ }^{16}$ Despite showing an intriguing trend toward proning benefit, limited subject recruitment failed to provide adequate statistical power, and the question of prone positioning for ARDS was not answered with this trial. Mancebo et al ${ }^{16}$ suggested that longer periods of prone positioning could be achieved safely, given the demonstrated lack of differences in complications. Unfortunately, they also did not achieve enough statistical power to exclude a difference in complications between the 2 groups. All that Mancebo et $\mathrm{al}^{16}$ could conclude was that prone positioning for longer periods of time may reduce mortality and that it was both feasible and safe.

Other investigators adopted the theory that earlier and longer prone positioning should result in a therapeutic effect. Fernandez et al ${ }^{19}$ recruited 42 subjects ( 21 prone, 19 supine) for their trial, which was aborted early. Using a standardized mechanical ventilation protocol in both experimental and control groups, prone subjects were maintained in that position for $20 \mathrm{~h} / \mathrm{d}$. With only 42 subjects, they did not show statistically significant differences in 60-d mortality, ICU stay, length of mechanical ventilation, or hospital days. ${ }^{19}$ They also failed to demonstrate a difference in pneumothorax, unplanned extubation, or ventilator-associated pneumonia. An improvement was shown in $\mathrm{P}_{\mathrm{aO}} / \mathrm{F}_{\mathrm{IO}_{2}}$ in the prone group on day 3, leading to their conclusion that early and continuous prone positioning in ARDS should not be dismissed.

Taccone et al ${ }^{17}$ recruited 342 subjects into a trial that randomized 168 subjects to undergo prone positioning for $20 \mathrm{~h} / \mathrm{d}$. They also segmented their patient populations into moderate $\left(\mathrm{P}_{\mathrm{aO}_{2}} / \mathrm{F}_{\mathrm{IO}_{2}}=100-200 \mathrm{~mm} \mathrm{Hg}, n=192\right)$ and severe $\left(\mathrm{P}_{\mathrm{aO}_{2}} / \mathrm{F}_{\mathrm{IO}_{2}}<100 \mathrm{~mm} \mathrm{Hg}, n=150\right)$ ARDS to test 
the theory that prone positioning may only show clinical benefit in the most severely ill subjects with ARDS. ${ }^{17}$ Taccone et al ${ }^{17}$ targeted $20 \mathrm{~h}$ and achieved $18 \pm 4 \mathrm{~h} / \mathrm{d}$ of prone positioning in the experimental group. They achieved adequate recruitment according to their power analysis to demonstrate a $15 \%$ improvement in mortality in the prone group. ${ }^{17}$ The relative risk and 95\% CI for 28-d mortality, ICU mortality, and 6-month mortality, respectively, for the entire population were: relative risk 0.97 (CI $0.84-1.13$, $P=.72)$, relative risk $0.94(\mathrm{CI} 0.79-1.12, P=.47)$, and relative risk 0.90 (CI $0.73-1.11, P=.33$ ). The same outcomes for the moderate hypoxemia and severe hypoxemia subgroups were: relative risk 1.04 (CI 0.89-1.22, $P=.62$ ), relative risk $1.00(\mathrm{CI} 0.83-1.22, P=.97)$, and relative risk 0.98 (CI $0.76-1.25, P=.85$ ) and relative risk 0.87 (CI $0.66-1.14, P=.31$ ), relative risk 0.83 (CI $0.60-1.15$, $P=.25$ ), and relative risk 0.78 (CI $0.53-1.14) .{ }^{17}$ Given these data, they cited a trend favoring prone positioning in the severe hypoxemia group but failed to demonstrate an improvement in any of their primary or secondary outcomes. ${ }^{17}$ Taccone et al ${ }^{17}$ encountered more complications with prone positioning.

It is on the basis of these RCTs that Guérin et $\mathrm{al}^{20}$ formulated selection criteria and a protocol that finally demonstrated a statistically significant outcome benefit to prone positioning in subjects with severe ARDS. Although the findings in the work of Guérin et $\mathrm{al}^{20}$ are impressive, it must be stressed that the results were obtained in subjects encountering a specific set of circumstances; therefore, the benefit implied by their results would not be applicable to the global population of patients with ARDS. Earlier studies included subjects with somewhat less severe lung disease. For instance, the $\mathrm{P}_{\mathrm{aO}_{2}} / \mathrm{F}_{\mathrm{IO}_{2}}$ ranged from 125 to $228 \mathrm{~mm} \mathrm{Hg}$ at inclusion in studies that failed to show a clinical benefit from prone positioning, whereas the $\mathrm{P}_{\mathrm{aO}_{2}} / \mathrm{F}_{\mathrm{IO}_{2}}$ in the study by Guérin et al ${ }^{20}$ was 100 in both groups (required to be $<150$ for inclusion). A meta-analysis performed by Alsaghir et $\mathrm{al}^{21}$ was not able to demonstrate a mortality difference favoring prone positioning when combining the data of 6 trials from 2001 to 2006. When they looked only at subjects from Gattinoni et al ${ }^{14}$ and Mancebo et al ${ }^{16}$ with Simplified Acute Physiology II scores $>50$, however, they noted a significant difference that favored proning. ${ }^{21}$ Although there may be a benefit to prone positioning for patients with severe ARDS, it is unlikely to improve mortality risk for patients with less severe disease.

A second factor to consider when evaluating the results of Guérin et $\mathrm{a}^{20}$ is how conventional mechanical ventilation techniques in ARDS have changed over time. It is now clear that lung-protective mechanical ventilation techniques improve survival in ARDS. ${ }^{3-6,27}$ In a meta-analysis, Beitler et $\mathrm{al}^{22}$ evaluated the mean $\mathrm{V}_{\mathrm{T}}$ of several randomized controlled trials of prone positioning conducted from
2001 through 2013. In that work (as opposed to the post hoc subgroup analysis of Gattinoni et $\mathrm{al}^{14}$ ), prone positioning did not improve mortality outcome in subjects receiving higher average tidal volumes $(>8 \mathrm{~mL} / \mathrm{kg}$ of ideal body weight).22 The combined effect of prone positioning and lower average $\mathrm{V}_{\mathrm{T}}(\leq 8 \mathrm{~mL} / \mathrm{kg}$ of ideal body weight) did favor treatment. It is important to recognize that lungprotective ventilation techniques have had a significant impact on outcomes in ARDS over the period of time that prone positioning trials have taken place.$^{52}$ Although some data from the first Italian trial imply the converse, it is conceivable that prone positioning for patients with severe ARDS is only effective when lung-protective mechanical ventilation is employed.

Lung-protective ventilation is not consistently used by many providers who confront ARDS. ${ }^{53,54} \mathrm{~A}$ recent report indicated that an initial failure to recognize ARDS followed by transition to lung-protective mechanical ventilation increased mortality between 2.7 and $7.2 \%$, depending on the size of the tidal volume used. ${ }^{55}$ Before widespread implementation of prone positioning protocols, providers should ensure that best-practice lung-protective ventilation is being provided for their patients with ARDS.

A third factor that should be weighed when considering the merits of prone positioning, as demonstrated by Guérin et $\mathrm{al}^{20}$ is that most subjects in this trial received NMBAs to facilitate care. In 2010, Papazian et $\mathrm{al}^{9}$ performed a multi-center, double-blind, placebo-controlled trial of subjects with severe ARDS $\left(\mathrm{P}_{\mathrm{aO}_{2}} / \mathrm{F}_{\mathrm{IO}_{2}}<150 \mathrm{~mm} \mathrm{Hg}\right)$ randomized to receive either NMBAs (cisatracurium besylate) or placebo. These investigators reported a 90-d hazard ratio of death of 0.68 (CI $0.48-0.98, P=.04$ ) in subjects receiving NMBAs compared with subjects receiving placebo. ${ }^{9}$ In that trial, both groups received a statistically similar number of therapeutic co-interventions, such as prone positioning (NMBA $42 \%$ vs placebo $48 \%, P=.31$ ), suggesting that these co-interventions were not key factors in demonstrating a clinical effect. Similarly a meta-analysis by Alhazzani et al ${ }^{56}$ evaluating 3 trials and a total of 431 subjects (NMBA 223, control 208) demonstrated a risk ratio of 0.72 (CI $0.28-0.91$ ) for 90-d hospital mortality favoring treatment with NMBAs. Guérin et $\mathrm{al}^{20}$ recognized the potential role of NMBAs and adjusted for their use in their final analysis because fewer subjects in the supine group received NMBAs. Judging from the analyses of Papazian et $\mathrm{al}^{9}$ and Alhazzani et al, ${ }^{56}$ the reduced early use of NMBAs might have affected mortality in the supine group of Guérin et al. ${ }^{20}$

Complications can occur with prone positioning. Multiple studies have reported an increased risk of pressure ulcers in the prone group. ${ }^{14,15,57}$ Risk factors associated with pressure ulcers included age $\geq 60 \mathrm{y}$, male sex, and body mass index $\geq 28.4 \mathrm{~kg} / \mathrm{m}^{2} .33,57$ Because the risk ratio for pressure ulcers was higher in the more recent trial by 
Table 2. Exclusion Criteria Observed in the Key Prone Versus Supine ARDS Clinical Trials

\begin{tabular}{|c|c|c|c|c|c|c|}
\hline Exclusions to Prone Positioning & $\begin{array}{l}\text { Gattinoni }^{14} \\
(2001)\end{array}$ & $\begin{array}{l}\text { Guérin }^{15} \\
(2004)\end{array}$ & $\begin{array}{c}\text { Mancebo }^{16} \\
(2006)\end{array}$ & $\begin{array}{l}\text { Fernandez }^{19} \\
(2008)\end{array}$ & $\begin{array}{l}\text { Taccone }^{17} \\
(2009)\end{array}$ & $\begin{array}{c}\text { Guérin }^{20} \\
(2013)\end{array}$ \\
\hline Tracheal surgery or sternotomy & & $x$ & & & & $x$ \\
\hline Massive hemoptysis & & $\times$ & & & & $x$ \\
\hline Bronchopleural fistula & & $\times$ & & & & \\
\hline Facial trauma/surgery & & & & & & $x$ \\
\hline Unstable ortho/spine & $x$ & $\times$ & $\times$ & $x$ & $\times$ & $x$ \\
\hline Severe hypotension, MAP $<65$ or $<80$ & $x$ & $\times$ & $\times$ & $x$ & $\times$ & $x$ \\
\hline Pregnancy & & & $\times$ & & & $x$ \\
\hline Inhaled nitric oxide & & & & & & $\times$ \\
\hline Lung or other transplantation & & & & & $\times$ & $\times$ \\
\hline Burns $>20 \%$ TBSA & & & & & & $x$ \\
\hline Chronic respiratory failure on oxygen or NIV & & $\times$ & & & & $\times$ \\
\hline Cerebral edema or elevated ICP & $x$ & $x$ & $\times$ & $\times$ & $\times$ & $x$ \\
\hline Cardiogenic pulmonary edema & $x$ & $x$ & & & & \\
\hline Recent pacemaker implantation & & $x$ & & & & $x$ \\
\hline Anterior chest tube & & & & & & $\times$ \\
\hline $\begin{array}{l}\text { Of note, the single trial to demonstrate a statistically significar } \\
\text { MAP = mean arterial pressure }(\mathrm{mm} \mathrm{Hg}) \\
\text { TBSA = total body surface area } \\
\text { NIV = noninvasive ventilation } \\
\text { ICP = intracranial pressure }\end{array}$ & tality benefit to $\mathrm{p}$ & sitioning im & nost numerou & rictive exclusio & & \\
\hline
\end{tabular}

Guérin et al, ${ }^{20}$ the hazard would seem to increase with longer prone sessions..$^{33,57}$ The nature of the supporting bed surface may influence the tendency for ulceration. Other complications of prone positioning are also important. Taccone et $\mathrm{al}^{17}$ reported an increased rate of airway obstruction, transient desaturation, vomiting, increased vasopressor needs, loss of venous access, displacement of endotracheal tubes, and the need for increased neuromuscular blockers with prone positioning. Other studies have listed airway complications, venous and arterial access problems, facial edema, and vomiting as problems associated with the prone position. ${ }^{58}$ The decision to employ prone positioning for an individual patient requires a risk/benefit analysis specific to the individual patient and the context of their care. Many of the more concerning complications of prone positioning occur during the initial turning. These potentially can be overcome with careful and regimented prone positioning protocols. ${ }^{43,57,58}$ To instruct users and readers how to duplicate their positioning method, a protocol is described, and video recordings are provided in the supplement to Guérin et al. ${ }^{20}$ Successful trials reporting no differences in rates of important complications between prone and supine positioning groups have employed these types of nursing protocols. These procedures require adequate numbers of staff to be present during positioning, adequate training of the staff involved in the process, and appropriate exclusion of patients at high risk for prone complications. Guérin et $\mathrm{al}^{20}$ reported that all centers involved in their study had $\geq 5 \mathrm{y}$ of experience in prone positioning. ${ }^{20}$ They also imposed extensive clinically relevant exclusion criteria, which included mechanical ventilation for ARDS $\geq 36 \mathrm{~h}$; intracranial pressure $>30 \mathrm{~mm} \mathrm{Hg}$; cerebral perfusion pressure $<60 \mathrm{~mm} \mathrm{Hg}$; massive hemoptysis; recent tracheal surgery or sternotomy; recent serious facial trauma or surgery; recent deep venous thrombosis; recent pacemaker placement; unstable spine, femur, or pelvic fractures; mean arterial pressure $<65 \mathrm{~mm} \mathrm{Hg}$; pregnancy; single anterior chest tube with air leaks; lung transplantation; $>20 \%$ total body surface area burn; chronic respiratory failure; underlying disease with life expectancy $<1 \mathrm{y}$; use of inhaled nitric oxide or almitrine bismesylate; use of extracorporeal membrane oxygenation; and use of noninvasive ventilation delivered for $>24 \mathrm{~h}$ before inclusion (Table 2). ${ }^{20}$ Indeed, $<15 \%$ of patients with ARDS admitted to the participating ICUs during the study period were randomized into the study. Since improved outcomes with prone positioning could only be demonstrated in selected patient populations treated in highly trained ICUs, expansion of this therapy to a broad population of patients and clinical settings must be considered carefully.

Despite the physiologic rationality of prone positioning, it is notable that of the multiple randomized trials of prone positioning, only Guérin et al ${ }^{20}$ demonstrated statistically significant improvement of mortality rate with proning therapy. Inclusion of only subjects with severe ARDS, use of appropriate lung-protective ventilation, liberal use of NMBAs, substantial institutional experience proning patients, and exclusion of patients likely to experience complications from prone positioning are important factors to 


\section{Early Prone Positioning IN ARDS}

be considered when attempting to apply the results of Guérin et $\mathrm{al}^{20}$ to local practice. Comparing Guérin et $\mathrm{al}^{15}$ and Guérin et al, ${ }^{20}$ mortality in the prone group improved from 41.1 to $20.1 \% .^{15,20,25}$ Aside from increased duration of prone positioning from 8 to $16 \mathrm{~h}$, the major differences in the studies from 2004 to 2013 were exactly the factors discussed above. These factors included a baseline inclusion $\mathrm{P}_{\mathrm{aO}_{2}} / \mathrm{F}_{\mathrm{IO}_{2}}$ criterion that decreased from 150 to $100 \mathrm{~mm} \mathrm{Hg}$. Mechanical ventilation protocols went from undefined with mean $\mathrm{V}_{\mathrm{T}}$ of $8.1 \mathrm{~mL} / \mathrm{kg}$ of ideal body weight to standard lung-protective ventilation with mean $\mathrm{V}_{\mathrm{T}}$ of $7 \mathrm{~mL} / \mathrm{kg}$ of ideal body weight. The use of NMBAs went from clinician preference to protocolized and extensive use of NMBAs in 2013. Prone positioning techniques were early in development and disseminated as guidelines to study centers in 2004, whereas in 2013 , only centers were used with substantial experience coupled with multimediabased training about prone positioning. It seems implausible that the increased duration of prone positioning was the only factor leading to a theoretical $20 \%$ absolute risk reduction in the prone groups from 2004 to 2013.

Although the study of Guérin et a ${ }^{20}$ aptly demonstrates that prone positioning can have a beneficial effect in ARDS, it does not suggest that all patients with ARDS will benefit from proning. Although patients with severe, early phase ARDS may benefit, prone positioning should not be viewed as a general standard of care for all ARDS patients. Prone positioning protocols should only be utilized once healthcare systems have invested in improving compliance with lung-protective mechanical ventilation and the use of NMBAs. Once this has been accomplished, prone positioning should only be considered in severe ARDS, in patients who are not at a high risk for prone complications, and in settings trained to provide a safe and effective prone positioning technique.

\section{REFERENCES}

1. Bernard GR, Artigas A, Brigham KL, Carlet J, Falke K, Hudson L, et al. The American-European Consensus Conference on ARDS: definitions, mechanisms, relevant outcomes, and clinical trial coordination. Am J Respir Crit Care Med 1994;149(3 Pt 1):818-824.

2. ARDS Definition Task Force, Ranieri VM, Rubenfeld GD, Thompson BT, Ferguson ND, Caldwell E, Slutsky AS. Acute respiratory distress syndrome: the Berlin Definition. JAMA 2012;307(23):25262533.

3. The Acute Respiratory Distress Syndrome Network. Ventilation with lower tidal volumes as compared with traditional tidal volumes for acute lung injury and the acute respiratory distress syndrome. N Engl J Med 2000;342(18):1301-1308.

4. Amato MB, Barbas CS, Medeiros DM, Magaldi RB, Schettino GP, Lorenzi-Filho G, et al. Effect of a protective-ventilation strategy on mortality in the acute respiratory distress syndrome. N Engl J Med 1998;338(6):347-354.

5. Villar J, Kacmarek RM, Pérez-Méndez L, Aguirre-Jaime A. A high positive end-expiratory pressure, low tidal volume ventilatory strategy improves outcome in persistent acute respiratory distress syn- drome: a randomized, controlled trial. Crit Care Med 2006;34(5): 1311-1318

6. Petrucci N, De Feo C. Lung protective ventilation strategy for the acute respiratory distress syndrome. Cochrane Database Syst Rev 2013;(2):CD003844.

7. Brower RG, Lanken PN, MacIntyre N, Matthay MA, Morris A, Ancukiewicz M, et al. Higher versus lower positive end-expiratory pressures in patients with the acute respiratory distress syndrome. N Engl J Med 2004;351(4):327-336.

8. Briel M, Meade M, Mercat A, Brower RG, Talmor D, Walter SD, et al. Higher vs lower positive end-expiratory pressure in patients with acute lung injury and acute respiratory distress syndrome: systematic review and meta-analysis. JAMA 2010;303(9):865-873.

9. Papazian L, Forel JM, Gacouin A, Penot-Ragon C, Perrin G, Loundou A, et al. Neuromuscular blockers in early acute respiratory distress syndrome. N Engl J Med 2010;363(12):1107-1116.

10. Piehl MA, Brown RS. Use of extreme position changes in acute respiratory failure. Crit Care Med 1976;4(1):13-14.

11. Pelosi P, D'Andrea L, Vitale G, Pesenti A, Gattinoni L. Vertical gradient of regional lung inflation in adult respiratory distress syndrome. Am J Respir Crit Care Med 1994;149(1):8-13.

12. Gattinoni L, Taccone P, Carlesso E, Marini JJ. Prone position in acute respiratory distress syndrome: rationale, indications, and limits. Am J Respir Crit Care Med 2013;188(11):1286-1293.

13. Gattinoni L, Pesenti A, Carlesso E. Body position changes redistribute lung computed-tomographic density in patients with acute respiratory failure: impact and clinical fallout through the following 20 years. Intensive Care Med 2013;39(11):1909-1915.

14. Gattinoni L, Tognoni G, Pesenti A, Taccone P, Mascheroni D, Labarta $\mathrm{V}$, et al. Effect of prone positioning on the survival of patients with acute respiratory failure. N Engl J Med 2001;345(8):568-573.

15. Guérin C, Gaillard S, Lemasson S, Ayzac L, Girard R, Beuret P, et al. Effects of systematic prone positioning in hypoxemic acute respiratory failure: a randomized controlled trial. JAMA 2004; 292(19):2379-2387.

16. Mancebo J, Fernández R, Blanch L, Rialp G, Gordo F, Ferrer M, et al. A multicenter trial of prolonged prone ventilation in severe acute respiratory distress syndrome. Am J Respir Crit Care Med 2006;173(11):1233-1239.

17. Taccone P, Pesenti A, Latini R, Polli F, Vagginelli F, Mietto C, et al. Prone positioning in patients with moderate and severe acute respiratory distress syndrome: a randomized controlled trial. JAMA 2009; 302(18):1977-1984.

18. Sud S, Friedrich JO, Taccone P, Polli F, Adhikari NK, Latini R, et al. Prone ventilation reduces mortality in patients with acute respiratory failure and severe hypoxemia: systematic review and meta-analysis. Intensive Care Med 2010;36(4):585-599.

19. Fernandez R, Trenchs X, Klamburg J, Castedo J, Serrano JM, Besso $\mathrm{G}$, et al. Prone positioning in acute respiratory distress syndrome: a multicenter randomized clinical trial. Intensive Care Med 2008;34(8): 1487-1491.

20. Guérin C, Reignier J, Richard JC, Beuret P, Gacouin A, Boulain T, et al. Prone positioning in severe acute respiratory distress syndrome. N Engl J Med 2013;368(23):2159-2168.

21. Alsaghir AH, Martin CM. Effect of prone positioning in patients with acute respiratory distress syndrome: a meta-analysis. Crit Care Med 2008;36(2):603-609.

22. Beitler JR, Shaefi S, Montesi SB, Devlin A, Loring SH, Talmor D, Malhotra A. Prone positioning reduces mortality from acute respiratory distress syndrome in the low tidal volume era: a meta-analysis. Intensive Care Med 2014;40(3):332-341.

23. Oksenberg A, Silverberg DS. The effect of body posture on sleeprelated breathing disorders: facts and clinical implications. Sleep Med Rev 1998;2(3):139-162. 


\section{EARly Prone Positioning In ARDS}

24. Broccard AF, Shapiro RS, Schmitz LL, Ravenscraft SA, Marini JJ. Influence of prone position on the extent and distribution of lung injury in a high tidal volume oleic acid model of acute respiratory distress syndrome. Crit Care Med 1997;25(1):16-27.

25. Lamm WJ, Graham MM, Albert RK. Mechanism by which the prone position improves oxygenationin acute lung injury. Am J Respir Crit Care Med 1994;150(1):184-193.

26. Pelosi P, Brazzi L, Gattinoni L. Prone position in acute respiratory distress syndrome. Eur Respir J 2002;20(4):1017-1028.

27. Gillart T, Bazin JE, Guelon D, Constantin JM, Mansoor O, Conio N, Schoeffler P. Effect of bronchial drainage on the improvement in gas exchange observed in ventral decubitus in ARDS Ann Fr Anesth Reanim 2000;19(3):156-163.

28. Albert RK, Hubmayr RD. The prone position eliminates compression of the lungs by the heart Am J Respir Crit Care Med 2000; 161(5):1660-1665.

29. Wiener CM, Kirk W, Albert RK. Prone position reverses gravitational distribution of perfusion in dog lungs with oleic acid-induced injury. J Appl Physiol 1990;68(4):1386-1392.

30. Broccard A, Shapiro RS, Schmitz LL, Adams AB, Nahum A, Marini JJ. Prone positioning attenuates and redistributes ventilator-induced lung injury in dogs. Crit Care Med 2000;28(2):295-303.

31. Valenza F, Guglielmi M, Maffioletti M, Tedesco C, Maccagni P, Fossali T, et al. Prone position delays the progression of ventilatorinduced lung injury in rats: does lung strain distribution play a role? Crit Care Med 2005;33(2):361-367.

32. Gattinoni L, Vagginelli F, Carlesso E, Taccone P, Conte V et al. Decrease in $\mathrm{P}_{\mathrm{aCO}}$, with prone position is predictive of improved outcome in acute respiratory distress syndrome. Crit Care Med 2003; 31(12):2727-2733.

33. Lee JM, Bae W, Lee YJ, Cho YJ. The efficacy and safety of prone positional ventilation in acute respiratory distress syndrome: updated study-level meta-analysis of 11 randomized controlled trials Crit Care Med 2014;42(5):1252-1262.

34. Sackett DL, Rosenberg WM, Gray JA, Haynes RB, Richardson WS. Evidence based medicine: what it is and what it isn't. BMJ 1996; 312(7023):71-72.

35. Hubmayr RD, Walters BJ, Chevalier PA, Rodarte JR, Olson LE. Topographical distribution of regional lung volume in anesthetized dogs. J Appl Physiol Respir Environ Exerc Physiol. 1983;54(4): 1048-1056.

36. Pelosi P, Goldner M, McKibben A, Adams A, Eccher G, Caironi P, et al. Recruitment and derecruitment during acute respiratory failure: an experimental study. Am J Respir Crit Care Med 2001;164(1):122130.

37. Marini JJ, Gattinoni L. Propagation prevention: a complementary mechanism for "lung protective" ventilation in acute respiratory distress syndrome. Crit Care Med 2008;36(12):3252-3258.

38. Chatte G, Sab JM, Dubois JM, Sirodot M, Gaussorgues P, Robert D. Prone position in mechanically ventilated patients with severe acute respiratory failure. Am J Respir Crit Care Med 1997;155(2):473478.

39. Makiyama AM, Gibson LJ, Harris RS, Venegas JG. Stress concentration around an atelectatic region: a finite element model. Respir Physiol Neurobiol 2014;201:101-110.

40. Jozwiak M, Teboul JL, Anguel N, Persichini R, Silva S, Chemla D, et al. Beneficial hemodynamic effects of prone positioning in patients with acute respiratory distress syndrome. Am J Respir Crit Care Med 2013;188(12):1428-1433.

41. Vieillard-Baron A, Charron C, Caille V, Belliard G, Page B, Jardin F. Prone positioning unloads the right ventricle in severe ARDS. Chest 2007;132(5):1440-1446.
42. Amato MB, Meade MO, Slutsky AS, Brochard L, Costa EL, Schoenfeld DA, et al. Driving pressure and survival in the acute respiratory distress syndrome. N Engl J Med 2015;372(8):747-755.

43. Messerole E, Peine P, Wittkopp S, Marini JJ, Albert RK. The pragmatics of prone positioning. Am J Respir Crit Care Med 2002; 165(10):1359-1363.

44. Graf J, Mentzelopoulos SD, Adams AB, Zhang J'. Tashjian J, Marini JJ. Semi-quantitative tracking of intra-airway fluids by computed tomography. Clin Physiol Funct Imaging 2009;29(6):406-413.

45. Erickson SE, Martin GS, Davis JL, Matthay MA, Eisner MD, NIH NHLBI ARDS Network. Recent trends in acute lung injury mortality: 1996-2005. Crit Care Med 2009;37(5):1574-1579.

46. Gattinoni L, Caironi P, Cressoni M, Chiumello D, Ranieri VM, Quintel M, et al. Lung recruitment in patients with the acute respiratory distress syndrome. N Engl J Med 2006;354(17):1775-1786.

47. Chiumello D, Carlesso E, Cadringher P, Caironi P, Valenza F, Polli $\mathrm{F}$, et al. Lung stress and strain during mechanical ventilation for acute respiratory distress syndrome. Am J Respir Crit Care Med 2008;178(4):346-355.

48. Chiumello D, Cressoni M, Carlesso E, Caspani ML, Marino A, Gallazzi E, et al. Bedside selection of positive end-expiratory pressure in mild, moderate, and severe acute respiratory distress syndrome. Crit Care Med 2014;42(2):252-264.

49. Kloot TE, Blanch L, Melynne Youngblood A, Weinert C, Adams $\mathrm{AB}$, Marini JJ, et al. Recruitment maneuvers in three experimental models of acute lung injury: effect on lung volume and gas exchange. Am J Respir Crit Care Med 2000;161(5):1485-1494.

50. Caramez MP, Kacmarek RM, Helmy M, Miyoshi E, Malhotra A, Amato MB, Harris RS. A comparison of methods to identify openlung PEEP. Intensive Care Med. 2009;35(4):740-747.

51. Brodie D, Bacchetta M. Extracorporeal membrane oxygenation for ARDS in adults. N Engl J Med 2011;365(20):1905-1914.

52. Kallet RH, Jasmer RM, Pittet JF, Tang JF, Campbell AR, Dicker R, et al. Clinical implementation of the ARDS network protocol is associated with reduced hospital mortality compared with historical controls. Crit Care Med 2005;33(5):925-929.

53. Wolthuis EK, Kesecioglu J, Hassink LH, Determann RM, Korevaar JC, Schultz MJ. Adoption of lower tidal volume ventilation improves with feedback and education. Respir Care 2007;52(12):1761-1766.

54. Joynes E, Dalay S, Patel JM, Fayek S. A complete audit cycle to assess adherence to a lung protective ventilation strategy. Indian J Crit Care Med 2014;18(11):746-749.

55. Needham DM, Yang T, Dinglas VD, Mendez-Tellez PA, Shanholtz C, Sevransky JE, et al. Timing of low tidal volume ventilation and intensive care unit mortality in acute respiratory distress syndrome: a prospective cohort study. Am J Respir Crit Care Med 2015;191(2): 177-185.

56. Alhazzani W, Alshahrani M, Jaeschke R, Forel JM, Papazian L, Sevransky J, Meade MO. Neuromuscular blocking agents in acute respiratory distress syndrome: a systematic review and meta-analysis of randomized controlled trials. Crit Care 2013;17(2):R43.

57. Girard R, Baboi L, Ayzac L, Richard JC, Guérin C, Proseva trial group. The impact of patient positioning on pressure ulcers in patients with severe ARDS: results from a multicentre randomised controlled trial on prone positioning. Intensive Care Med 2014;40(3): 397-403.

58. De Jong A, Molinari N, Sebbane M, Prades A, Futier E, Jung B, et al. Feasibility and effectiveness of prone position in morbidly obese patients with ARDS: a case-control clinical study. Chest 2013;143(6): 1554-1561. 


\section{Discussion}

Branson: How many people would use prone positioning in a patient with a $\mathrm{P}_{\mathrm{aO}_{2}} / \mathrm{F}_{\mathrm{IO}_{2}}<150$ in their ICU?

Hurford: As standard of care? Everybody with a $\mathrm{P}_{\mathrm{aO}_{2}} / \mathrm{F}_{\mathrm{IO}_{2}}<150$ gets proned?

Branson: No, nothing's absolute. I need to phrase it better.

Marini: It's for someone who's refractory and you're entering dangerous pressure and $\mathrm{F}_{\mathrm{IO}_{2}}$.

MacIntyre: Is there anybody who would never prone anybody?

Kacmarek: All of us prone some patients. I put prone positioning after recruitment and appropriate titration of PEEP. If you do that and you don't see a reasonable response over a period of time, then I would consider prone positioning. But I don't think you should consider it before you've done everything else because to me the potential negative effects of prone positioning clearly outweigh the negative effects of lung recruitment.

Berra: When I think about ARDS and proning, I always think about small airways obstruction, mucociliary clearance, and secretion drainage. Especially in difficult to ventilate ARDS patients with dishomogenous lungs, parenchymas, and such. So one of the beneficial effects of proning is to drain fluid/secretions. Is there a study on mucociliary clearance and proning? And the drainage of secretions in ARDS patients?

Marini: I'm not aware of any studies on the mucociliary escalator. Lorenzo [Berra], airway clearance is something you're really adept at. I think airway drainage is often a big part of why many people do better in the prone position. How do we expect our suction catheters to clear out the distal airways without a little help from gravity? Maybe I interpreted the question incorrectly, but should it be the next thing you try after you run out of the usual things? I would say yes, it should be. Increasing PEEP without recruitment has been repeatedly shown ${ }^{1}$ to redirect blood flow to compromised zones, overstretching some areas and upping the ante for damage at the interface zone. If you keep using PEEP and recruitment maneuvers to higher and higher values in the supine position, you're really swimming upstream. You're going to wind up with a hemodynamic problem and actually are not doing your patient very much good. If you've tried PEEP and you've reached a reasonable level and your $\mathrm{F}_{\mathrm{IO}_{2}}$ is still a little high and you're uneasy, then turning them over almost certainly reduces the risk of ventilator-induced lung injury. We talked this morning about how driving pressures $>12$ or $14 \mathrm{~cm} \mathrm{H}_{2} \mathrm{O}$ potentially could be dangerous. If proning does not improve the patient's oxygenation or ventilation, then I think you need to let $6 \mathrm{~h}$ go by and turn them back to supine positioning, try more upright positioning, and try whatever you think might work.

I interpret the term standard of care to be a trusted intervention that should be a fallback option. It's not for everybody, for sure. But it is for those really in danger from ventilatorinduced lung injury or the consequences of hypoxemia. Complications are few, and safe proning is not difficult. In the Italian studies-and Lorenzo can probably correct me because he knows details about themthe bedding surface was firm and not selected to avoid skin breakdown. However, if you do have a surface which is padded, air-fluidized, or whatever you want to call it, the incidence of bedsores is quite small. If you pay attention to the head and to the skin surfaces and "swim" the patient every couple hours, they don't get into serious trouble with all those things we worry about. Nursing training is also key.

Holets: I think that's a good point. We do proning, but we use a specialty bed. There's a very big concern about developing decubiti, which is a reportable event. So, many times we don't keep them prone long enough.

Hurford: The question I have is where does it fall in the algorithm? Standard of care to me means everybody at a certain level will get it. Not necessarily just non-responders. Some people will get INO [inhaled nitric oxide] or inhaled prostacyclin or epoprostenol, and certainly I think among the group here, we would probably prone a patient before we did that. But we would probably do some other things before we would prone. Rather than, "oh the $\mathrm{P}_{\mathrm{aO}_{2}} / \mathrm{F}_{\mathrm{IO}_{2}}$ is $<150$, it's time to flip."

Marini: Bill, I agree with you completely. In our shop, we tend to go to inhaled prostacyclin first. If that doesn't stabilize the patient and we are still concerned, then we try proning; we're comfortable with it. We have nursing teams where only 2 nurses and a therapist will prone the patient. You generally need 2 or 3 persons. Once they're prone, they don't need a lot more care than a supine patient. I'm not talking down to anybody (you all know this), but once you have proned the patient, things really settle down. And generally speaking, yes, you have to have good surveillance but little more than you would normally do with supine patients.

Kallet: We've done proning in over 60 patients at San Francisco General, and a lot of what we do comes from what you've talked about. I agree with Bob [Kacmarek], we try to get people up to a neighborhood of 16-18 PEEP. After a few hours on PEEP at this range, some patients open up like a flower, and we can wean down their 
$\mathrm{F}_{\mathrm{IO}_{2}}$ without a problem. These patients don't need to be proned. However, there are other patients who fail to respond or show very modest improvements in $\mathrm{P}_{\mathrm{aO}}$, and these are the ones we prone. When I teach the residents about managing severe ARDS, I give them a guide that I call The Rule of Eights: If you're in the neighborhood of 18 of PEEP and $80 \%$ oxygen and you can't sustain a $\mathrm{P}_{\mathrm{aO}_{2}}$ of 80 while doing basic care, these are the ones we definitely prone. That's a pretty conservative strategy, but it's a way to push for prone therapy when some physicians are still squeamish about doing it. We've also occasionally witnessed trauma patients who fail to respond to high PEEP, and when we prone them, we very quickly drain several liters of pulmonary edema out their endotracheal tube! So perhaps these patients might have responded to high PEEP and diuretics. Since the PROSEVA study ${ }^{2}$ came out, we've noticed that our faculty and residents are not as hesitant to prone patients. The last thing I think is important to mention about the PROSEVA study ${ }^{2}$ and its stunning mortality results is that it was the most heavily protocolized study I've ever seen: sedation and paralysis, they had a protocol for fluid management, nutrition... I know how difficult it is to do a study like that, but perhaps that level of control over all aspects of therapy is what's needed to really improve outcomes.

Mireles-Cabodevila: In our institution, we have protocolized it as an adjunct therapy. That is, if you get to a $\mathrm{P}_{\mathrm{aO}_{2}} / \mathrm{F}_{\mathrm{IO}_{2}}<150$ and you've been there for $12 \mathrm{~h}$ on appropriate therapy, we will prone you. We just decided to do that as a group. A question that I had when John [Marini] was talking about the mechanism, you talked about the lung becoming stiffer, and when you the prone them the chest wall becoming stiffer. I remember one of the books in critical care mentioned the placement of bags on top of the chest like the poor man's proning. I wanted to hear from you guys what you thought about that and whether that had been tested?

Kacmarek: We've done it, but haven't done it in a long time, but it does seem to improve oxygenation by making the chest wall stiffer. It doesn't work in everybody, but it does improve $\mathrm{P}_{\mathrm{aO}_{2}}$ in some patients. You get redistribution of $\mathrm{V}_{\mathrm{T}}$ to the dependent as opposed to the non-dependent lung by putting weight on the thorax.

Marini: That might be a good idea; you're obviously not going to leave weights on the patient, but if you do see a response, that should be encouraging to turn the patient over. But if not, it does not exclude proning benefit. If you want to read good stuff on this, Paolo Pelosi did a great series of articles, ${ }^{3-5}$ where he found the chest wall stiffens but the lung improves its overall compliance. To take an obese patient and put them prone you stiffen their chest wall even further, but their FRC [functional residual capacity] improves, and their oxygenation improves.

Branson: Can we do rock-paperscissors? You've done optimal PEEP, you've done regular ventilator protection, you've done everything you can do with the regular ventilator. So, around the table: prone, INO/inhaled prostacyclin, or ECMO [extracorporeal membrane oxygenation]. Which one do you do first? The patient has refractory hypoxemia; what's your next step?

\section{Hurford: Prone, INO, ECMO.}

Davies: ECMO. We have proned some patients, but it's been a while; we take them off the oscillator and go to ECMO.

Holets: Prone, INO, ECMO.

Mireles-Cabodevila: Call for an ECMO consult, but we would start a rescue therapy of proning or inhaled prostacyclin.

Kacmarek: The way we're going lately we'd go to ECMO, but personally I think we should prone, then do INO or epoprostenol, and then ECMO. We're triggering ECMO consults much more frequently and more rapidly.

Kallet: At $\$ 180,000$ a pop, my hospital spent over $\$ 1,000,000$ in 18 months on ECMO. In response to that, we've mandated at least $24 \mathrm{~h}$ of bundling ARDS care with low- $\mathrm{V}_{\mathrm{T}}$, high PEEP, paralysis, inhaled prostacyclin, and proning. Since doing that, we've only needed to transfer one patient out for ECMO in almost $4 \mathrm{y}$.

Berra: I agree with Bob.

Marini: I'm not trying to make this complicated, but if your patient is acidotic and heading south from acidosis or renal insufficiency... ECMO might be the first option. Whether it's calling for an ECMO consult first or proning first would depend on the other organ systems. For us, again assuming that the patient is not seriously acidotic and/or hemodynamically unstable, we'd probably try inhaled prostacyclin because it's fast, and if that doesn't work like a charm, we'd prone next and lastly call for ECMO.

Kacmarek: The reflex is to go to inhaled vasodilator, but they do not change anything. For me, it's a cosmetic activity that does nothing to change the physiology that's creating the problem. So, yeah you can do it and you get good saturations for a while, but so what?

Marini: Unless it enables you to reduce the other things that could be injurious to the patient, I agree with you.

Hess: The reality that struck me, as John said, is how often we've done it 
and when is the last time we did it? We at the Massachusetts General Hospital don't prone very often. A handful per year, I would say. I think it's because we're more aggressive with PEEP and we do use a lot of inhaled pulmonary vasodilators. We actually don't use that much ECMO, either, for ARDS.

Mireles-Cabodevila: Do you put in an esophageal balloon?

Hess: Yes. Where some people would might say we're at a plateau pressure of 30 , so we need to put the patient on the oscillator or prone them or ECMO or whatever, we would lean toward putting in an esophageal balloon catheter and maybe we can violate the plateau pressure of 30 rule if we actually look at transpulmonary pressure.

Kacmarek: And we're doing that more and more these days.

\section{REFERENCES}

1. Petersson J, Ax M, Frey J, Sánchez-Crespo A, Lindahl SG, Mure M. Positive end-expiratory pressure redistributes regional blood flow and ventilation differently in supine and prone humans. Anesthesiology 2010;113(6):1361-1369.
2. Guérin C, Reignier J, Richard JC, Beuret P, Gacouin A, Boulain T, et al. Prone positioning in severe acute respiratory distress syndrome. N Engl J Med 2013; 368(23):2159-2168

3. Pelosi P, Cereda M, Foti G, Giacomini M, Pesenti A. Alterations of lung and chest wall mechanics in patients with acute lung injury: effects of positive end-expiratory pressure. Am J Respir Crit Care Med 1995; 152(2):531-537.

4. Pelosi P, Croci M, Ravagnan I, Vicardi P, Gattinoni L. Total respiratory system, lung, and chest wall mechanics in sedated-paralyzed postoperative morbidly obese patients. Chest 1996;109(1):144-151.

5. Pelosi P, Croci M, Calappi E, Mulazzi D, Cerisara M, Vercesi P, et al. Prone positioning improves pulmonary function in obese patients during general anesthesia. Anesth Analg 1996;83(3):578-583. 